\title{
Circuit
}

Musiques contemporaines

\section{An Electronic Music Studio for the Independent Composer (1964)}

\section{Gordon Mumma}

Volume 19, numéro 3, 2009

Pionniers canadiens de la lutherie électronique

URI : https://id.erudit.org/iderudit/038261ar

DOI : https://doi.org/10.7202/038261ar

Aller au sommaire du numéro

Éditeur(s)

Les Presses de l'Université de Montréal

ISSN

1183-1693 (imprimé)

1488-9692 (numérique)

Découvrir la revue

Citer cet article

Mumma, G. (2009). An Electronic Music Studio for the Independent Composer (1964). Circuit, 19(3), 85-90. https://doi.org/10.7202/038261ar d'utilisation que vous pouvez consulter en ligne.

https://apropos.erudit.org/fr/usagers/politique-dutilisation/ 
DOCUMENT

\section{An Electronic Music Studio for the Independent Composer (1964)}

Gordon Mumma

Gordon Mumma (né en 1935), compositeur américain (résidant au Canada depuis quelques années) et pionnier absolu dans le domaine de la live electronic music (cf. compte rendu de son disque paru dans le vol. 18, $n^{\circ} 2$ de Circuit) a publié le texte que voici dans le Journal of the Audio Engineering Society en 1964 (vol. 12, no 3, p. 240-244). Le " home studio » étant tout sauf banal à cette époque, cet article, reproduit intégralement ici, constitue un document historique qui témoigne de l'apparition de la figure du compositeur électronique indépendant. Cet article est reproduit avec l'aimable autorisation de Gordon Mumma et de l'Audio Engineering Society.

Jonathan Goldman 


\title{
An Electronic Music Studio for the Independent Comboser
}

\author{
Gordon Mumma
}

Ann Arbor, Michigan

\begin{abstract}
A description of an electronic music studio designed around the use of commercial highimpedance, high-fidelity equipment is presented, and the choice of equipment and its practical configuration for this application are considered. The article has two major objectives: (1) to present to the many composers who are interested in working in this medium an example of the potentialities of a lowcost independent studio, and (2) to indicate to the high-fidelity industry a special direction in which their research is sure to prove fruitful.
\end{abstract}

\section{INTRODUCTION}

FLECTRONIC MUSIC generally refers to music which $E_{\text {is }}$ composed directly on magnetic tape by electronic means. The interest of composers in producing music with electronic means is almost as old as the vacuum tube, ${ }^{1}$ but was not widely practiced as an art until magnetic tape facilities became available after the Second World War. In the relatively short time of less than two decades, electronic music has reached major importance as a radical force in the musical and artistic world. Most composers are seriously interested in the medium, and more than a few have actually worked with it.

The development of electronic music has produced many diverse compositional techniques and aesthetics. These include "musique concrete," which derives its sound materials from purely acoustical sources",3; "elektronische Musik", which is often rigorously serialized with techniques of additive waveform synthesis ${ }^{4}$; various combinations of these two approaches ${ }^{5,6}$; a music which uses elaborate programming procedures and computer simulation ${ }^{7,8,9} ;$ and, finally, a music which is performed in concert with prepared soundsources on tape by elaborate performance procedures on special playback equipment. ${ }^{10,11}$

Most electronic music has been composed in studios established by academic institutions, state-supported radio stations, and electronic-equipment manufacturers. ${ }^{\overline{ }}$ The major advantage of these institutional studios to the composer is the ready availability of specialized equipment and technicians to maintain it. However, the composer is often at a disadvantage because there are too few studios to accommodate all the composers interested in making electronic music, and those composers who are able to gain access to the busily scheduled institutional studios have too little time to compose.

The composer has the alternative of building his own studio and assuming the engineering and financial responsibilities himself. This task is not as awsome as might at first be imagined, particularly in the United States where a wide selection of high-fidelity components are available at reasonable cost. It should be understood, of course, that where economy is a major consideration in the construction of an independent studio, compromises may be necessary in the refinements and quality of certain types of equipment. Long-term stability and precise calibration is a refinement which invariably means higher cost and greater size.

Several independent studios have already been established. ${ }^{12}$ This article describes one such independent studio, The Cooperative Studio for Electronic Music, in Ann Arbor, Michigan, which was built by the composer Robert Ashley and the author.

Construction of the studio began in 1958, largely to fill the need for specially composed electronic music for the space-theatre of artist Milton Cohen, ${ }^{13-17}$ and for electronicmusic sound-tracks for the motion picture films of George Manupelli. ${ }^{17}$ The studio is comprised of three separate working areas, two for the composition of electronic music and a third for the performance of the music in conjunction 
with the work of Milton Cohen. It is the nature of the two working areas, or composition studios (Figs. 1 and 2), with which this article is concerned, since they serve as practical models of an electronic music studio for the independent composer.

The basic configuration of any electronic music studio can be divided conveniently into four parts: 1. general manipulation apparatus-tape transports, recording and playback amplifiers, and mixers; 2. sound sources-electronic oscillators and stored material of acoustical origin; 3. modification apparatus-filters and equalizers, transposition devices, gat ing and envelope control, and reverberation; and 4. accessories-power supplies; monitoring and analysis equipmen such as meters, loudspeakers, and the oscilloscope; splicers, the bulk eraser, etc.

Because of the practical reason of keeping the cost of an independent studio within modest limits, the basic premise was that it would be possible to design an electronic music studio using generally available high-impedance, high fidelity audio equipment. The cost was to correspond to the investment that a composer would make in a conventional musical instrument, and consideration and planning would be employed similar to that which a professiona musician would direct toward choosing his conventiona performing instrument.

An important consideration in the design philosophy for The Cooperative Studio for Electronic Music was to employ a maximum of "neutral" equipment. That is, since a large part of the compositional work of electronic_music is done with the manipulation and modification equipment, considerable effort was spent to make these components effective regardless of the nature of the sound-source material which might be employed. Filters and modulation apparatus, for instance, were designed to operate as separate component and are placeable anywhere in the equipment configuration. Thus the composer has considerable freedom to pursue whatever compositional technique or aesthetic he desires. This neutral equipment approach also extends to the humanengineering aspects of equipment configuration, which is no less important in the independent composer's low-cost studio than in a high-budget institutional laboratory.

The diverse high-fidelity industry has produced an abundance of products which are well-suited to the independent studio. Electronic and mechanical modifications, where desirable with this equipment, are basically simple. Only in the area of sound modification-where use is made of filtering, transposition, modulation, compression and expansion and envelope control procedures-is it necessary to construct special devices.

\section{DESIGN CONSIDERATIONS}

The choice of equipment for a basic studio depends upon the manipulation procedures the composer is likely to apply to his music. For instance, oscillators might not be necessary if the composer intended to work exclusively with sounds of acoustical origin and to forego those modulation procedures which require periodic waveforms as the modulating signal.

\section{Tape Transports}

Since most tape transports are powered by synchronous ac motors, they can be operated as continuously-variablespeed devices, with power supplied by a variable-frequency oscillator having suitable amplification and impedance matching. The oscillator and amplifier are likely to be a part of the studio anyway, and impedance matching to the capstan-drive motor can be accomplished with a variable autotransformer.

The most nearly ideal features for a tape transport are ease of modification for special head configurations and a mechanically simple drive mechanism.

The choice of basic speeds will be dictated by the probable application. Thus, 7.5 ips is the best compromise between tape economy and frequency response, 3.75 ips is suitable for tape storage of source material of limited bandwidth, and $15 \mathrm{ips}$ is desirable for detailed editing or extraordinary frequency requirements. The tape transport mechanism can but need not include preamplification and equalization.

\section{Preamplification and Equalization}

Separate preamplification and equalization equipment is available in a wide selection. Some units have provision for variable ac bias, and this valuable feature can be added to those which do not. Ideally, both the record bias and erase current should be separately controllable from the audiosignal component of the record current.

\section{Mixing}

Mixing appears to be the electronic process basic to most types of electronic music composition. The requirements for a mixer are usually met by any device which has wide, flat audio response, low distortion, and a high signal-to-noise ratio. Reverberation, when desired, is usually introduced at the mixing stage, and the Hammond-type device, which is usually sufficient, is available in several inexpensive forms for this purpose. Passive mixers are often adequate.

\section{Oscillators and Generators}

Several inexpensive oscillators of the efficient and stable Wien-bridge type are available. Most of these, however, do not extend their frequency range below $20 \mathrm{cps}$, and the sub-audio range from $20 \mathrm{cps}$ down to around five seconds per cycle is often of use in special modulation procedures.

Low-frequency extension of most commercial Wien-bridge oscillators is not difficult, and it may be worthwhile to consider separate construction of Wien-bridge or phase-shift oscillators for this purpose. Another reason for building special oscillators is to achieve wide frequency range in a single band if necessary. If more than two or three oscillators are desired, it may be ultimately less expensive and space-consuming to build them separately as a bank which is powered from a single, regulated power supply.

The basic harmonic-containing waveforms (sawtooth, pulse, square, and half-sine) are obtainable either with passive diode shapers or simple, active wave-shaping circuits, 
or they can be generated directly with multivibrators.

Thyratron gas tube or reverse-biased diode devices, with a stage of gain, are sufficient as noise generators, since the product does not have to meet stringent statistical requirements. Noise-band products are obtainable with accessory diode modulators in series.

\section{Modulation}

The basic processes of amplitude modulation and frequency (or phase) modulation have numerous applications. The uses of amplitude modulation include gating (or keying) and envelope control; volume compression and expansion; frequency spectrum transposition, inversion, compression, and expansion; and complex spectrum production. Useful frequency modulation applications include swept frequency spectra and diverse vibrato products.

Modulation apparatus suited for use in electronic music composition is not commercially available, but is neither difficult nor expensive to build. Passive semiconductor modulators are useful for complex spectrum generation and limited only by the quality and balance of their few simple components. With selective use, balanced diode bridge or ring modulators can be applied to gating and frequency transposition as well.

Active modulators range from the simple twin-triode cathode modulator or transistor emitter modulator, for use in gating, compression, and expansion, to more elaborate devices such as the balanced push-pull output type modulator with continuously variable control of the class of operation. This latter sophisticated device enables the composer to achieve sound-event sequencing without having to splice tape. The various types of passive and active balanced modulators, in conjunction with frequency filtering and wideband phase-shifting accessories, constitute an extremely important area of sound modification apparatus for electronic music composition.

\section{Filters}

Commercial bandpass filters might be considered beyond the budget of the independent composer, though they are no more expensive than some tape transports which might be seriously. considered. The active R-C comb filter probably represents the best single solution for the independent studio since it includes highpass, lowpass, bandpass, and band-elimination characteristics in one unit. A relatively inexpensive 9-octave version of such a filter, with a $28 \mathrm{db}$ slope per octave, has been commercially available. High, low, and bandpass filters with slopes of 12 to $24 \mathrm{db}$ per octave are attainable with as little as a single stage of gain and proper feedback, and are adaptable for resistance tuning. Frequency selective amplifiers with variable bandwidth and frequency can be designed employing the Wien-bridge, Twin- $\mathrm{T}$, or similar phase-shift devices.

Since many timbre-shaping efforts, including most "coloring" of white noise, do not require sharp cutoff filter characteristics, passive R-C-filter types are always useful. The composer who is interested primarily in shaping periodic waveforms and their modulation products with integration and differentiation procedures may find a few variable, passive R-C filters entirely sufficient for the needs of his studio.

\section{Accessories}

If several pieces of equipment such as active filters, modulators or oscillators are to be specially built, a separate regulated power supply may be the accessory of prime importance. An inexpensive oscilloscope, particularly if it includes dc amplifiers, can be of the greatest assistance, both in the construction of equipment and as a monitor for various composition processes, and of course supplies pulse and sawtooth waveforms over a wide range. The choice of further accessories depends upon their foreseeable applications.

\section{Configuration}

The final issue is the choice of studio configuration and equipment placement. For the independent composer in particular, who would be able to spend more time at the equipment than if he were sharing an institutional studio with many other composers, a flexible, or at least easily accessible, configuration would seem to be the most appropriate. This is important not only with regard to the fatigue contingent upon long hours of work, but also in order that the composer may be able to pursue a specific working aesthetic in depth and yet not ultimately find himself confined to that aesthetic because he has permanently bolted his equipment into place. This needs emphasis because the independent composer may have limited space in which to build his studio, and this immediately tends to dictate a fixed equipment configuration.

In this respect, however, the composer who builds his own studio with the type of equipment outlined in the introductory premise will also have an advantage over the composer who works with the rack-mounted or console-mounted laboratory apparatus found in most institutional studios. In sacrificing the precise calibration and great long-term stability of large-size laboratory equipment for the more compact proportions of high-impedance, high-fidelity components, a configuration can be arranged which will put the entire studio within arm's-reach of the comfortably seated composer (see Fig. 2).

With the possibility of an arm's-reach configuration, then, important consideration should be given to placement of the equipment requiring the most manipulation for the composer's chosen working procedure in a position which produces the least fatigue. Specific practical solutions to these problems can be illustrated in terms of the two working studios of the Cooperative Studio for Electronic Music.

The first of the two studios (Fig. 1), designed by Robert Ashley, employs three tape transports, associated playback and recording amplification, a five-channel mixer, an audiofrequency oscillator (sine, square, and pulse waveforms), a portable tape recorder for field work, and a monitor-amplifier with loudspeaker, all of which are commercially available. Specially constructed items include a reverberation device, passive $\mathrm{R}-\mathrm{C}$ filters, and a ring-bridge modulator. The few simple modifications applied to the commercially available equipment include special head configurations for 
the tape transports and continuously variable controls for the erase and record currents from the recording amplifier.

Three tape transports were chosen as the most convenient minimum from the studio, though with special head configurations and less working convenience it is possible to achieve the same mixing and modification results with only two transports. The transports were chosen largely because of their extremely simple mechanical design, which allowed modifications to be accomplished with relative ease.

The basic equipment of tape transports, preamplifiers, and the mixer is mounted in a fixed location on the apparatus panel. Supplementary equipment, such as reverberation, filtering, and switching devices, can be located according to the immediate desires of the composer.

The most important aspect of the configuration of this first studio is that the tape transports are mounted above the mixing and amplification equipment. Thus in a seated working position the composer has greatest access to the processes of electronic manipulation. As a result, Ashley has developed facile techniques of magnetic tape composition which rely almost exclusively on switching and mixing procedures and make little use of splicing or cutting of the tape itself. The tape transports are mounted vertically in such a way that elaborate loops can be routed conveniently

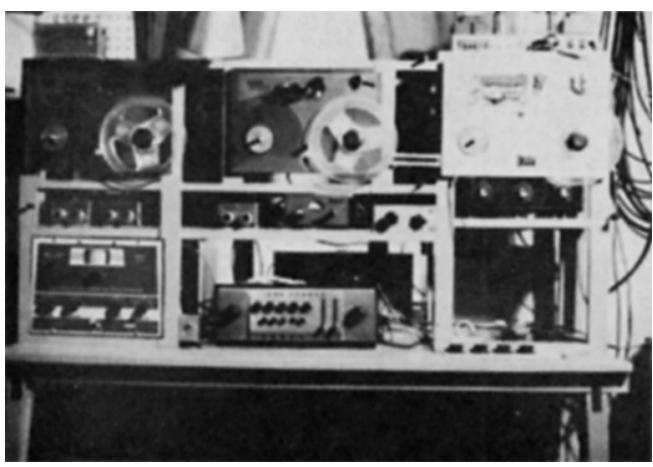

Fig. 1. Equipment installed in a studio for the composition of electronic music.

above the entire apparatus panel. By a special switching and monitoring procedure it is possible to record across two channels with a single recording amplifier.

The second of the two studios (Fig. 2), designed by the author, employs three tape transports, associated playback and recording amplification, two five-channel mixers, three audio-frequency sine and squarewave oscillators, a 9-octave comb filter, a Hammond-type reverberation device, an electronic switch, a regulated power supply, and monitor amplifiers with loudspeakers. These components represent the commercially available equipment. Modifications made to this equipment are the same as employed in the first studio, with the addition of a continuously-variable speed control for the tape transports (over two octaves range), lowfrequency extensions for the oscillators and electronic switch (to $0.2 \mathrm{cps}$ ), and improvement of the shielding and powersupply filtering for increased signal-to-noise ratios.

Special equipment includes wave-shapers for the oscillator outputs (half-sine, variable-width pulse, and sawtooth), passive diode-modulators, active cathode, emitter, and phase modulators, a variable-bias balanced-output modulator, a random noise generator, a frequency-selective amplifier with variable bandwidth, and miscellaneous active and passive $\mathrm{R}-\mathrm{C}$ filters. The remaining equipment, including an oscilloscope, $\mathrm{R}-\mathrm{C}$ bridge, and meters, is used in monitoring or the design of special equipment.

The basic equipment of tape transports, preamplifiers, and mixers, is not mounted in a fixed manner, and the configuration can be rearranged with a minimum of effort.

The most important aspect of the configuration of this second studio is that two tape transports are located below the mixing and amplification equipment (see right side of Fig. 2). These transports are mounted on special brackets,

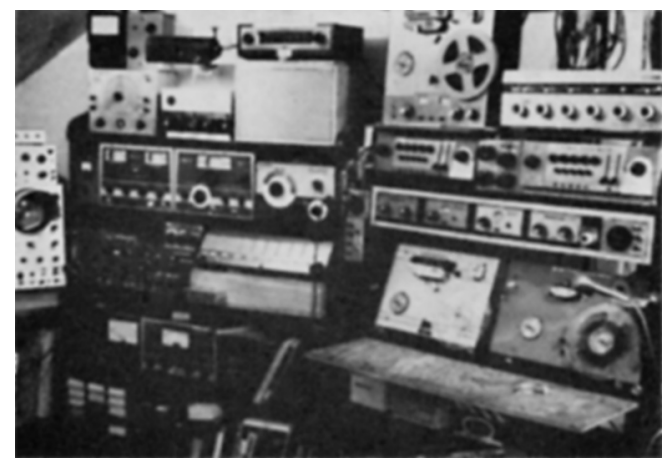

FIg. 2. A more elaborate electronic music studio than the one depicted in Fig. 1.

tilted back at a slight angle from the vertical, and can be moved forward onto the worktable. Splicing is thereby facilitated when the two transports are placed in the panel, and the use of loops is facilitated when these transports are placed forward on the worktable. The single upper tape transport with associated electronics is used primarily for dubbing and portable playback and recording. This entire apparatus panel is mounted on wheels and can be moved for easy access to the plugboards at the rear. The remaining equipment (see left side of Fig. 2), including the oscillators, modulators, and filters, remains stationary, since all the plugs are on the front of the panels.

The total cost of the first studio was less than $\$ 700.00$, and it was in operation within six months of its inception. It must be realized, however, that much of that time was spent in researching and selecting from the diversity of available equipment. By exact duplication a similar studio could be put into operation in a few weeks.

The total cost of the second studio was less than $\$ 2,000.00$, which under the premise stated in the introduction compares favorably with the cost of a grand piano. Though design 
experimentation still continues, operation of the second studio was effective within two years of its inception. The electronic-music-production part of the second studio could be duplicated in a few months, and since some of the equipment has proved sufficiently redundant, the cost of duplication could be held below $\$ 1,500.00$.

\section{REFERENCES}

1. Preiburg, F. K., Musica ex Machina, Ulstein Verlag, Berlin, 1960, pp. 9-47.

2. Schaffer, $\mathrm{P}, A$ la Recherche d'Une Musique Concrete, Editions du Seuil, Paris, 1952.

3. LeCaine, H., "Electronic Music", Proc. I.R.E., April 1956, pp. 474-476.

4. die Reihe, Vol. 1, "Electronic Music", Theodore Presser Co. Bryn Mawr, Pa., 1958

5. Hiller, L. A.. Jr., Report on Contemporary Experimental Music, 5. Hiller, L. A., Jr., Report on Contem
1961, Univ. of Illinois, Urbana, Ill. 1962.

6. Tall, J., "Music without Musicians", Saturday Review, Vol. 40 6. Tall, J., "Music witho
Jan. 26, 1957 , pp. $56-57$.

Jan. 26, 1957, pp. 56-57.
7. Olson, H. F., Belar, H., and Timmens, J., "Electronic Music 7. Olson, H. F., Belar, H., and Timmens, J., "Electronic
Synthesis", Jour. Acous. Soc. Am., Vol., 32, pp. 311-319, 1960.

8. Olson, H. F., and H. Belar, "Electronic Music Synthesizer", Jour. Acous. Soc. Am., Vol. 27, pp. 595-612, 1955.

9. Mathews, M. V., "An Acoustical Compiler for Music \& Psychological Stimuli", Bell System Tech. Jour., Vol. 40, pp. 677-694, 1961.

10. Hitchcock, H. W., "Current Chronicle", Musical Quarterly, Vol. XLVIII, No. 2, April 1962, p. 244.

11. Yates, P., "Music", Arts and Architecture, June 1963, p. 8

12. The composers Ramon Sender and Murtunin Subatnick estab lished The San Francisco Tape Music Center. In Cambridge, England the composer Roberto Gerhard fulfills a busy schedule of lectronic music commissions for the B.B.C. Henry Jacobs established his own studio in conjunction with film-maker Jordan Belsen "Vortex" presentations at the Morrison Planetarium in San Francisco.

13. Ashton, D. "Art", Arts and Architecture, May 1961, p. 7

14. Kuh, K., "The Fine Arts-Fascinating Rythms in Sculpture", Saturday Review, Vol. 44, July, 1961, p. 30

15. Cohen, M., "Space Theatre", Arts and Architecture, Aug. 1962, p. 10 .
16. Hedjmadi, P., "The Dome of Light", Illustraied Weekly of India, October 2, 1960

17. Manupelli, G., "Films and Photography", School Arts, Vol. 62, No. 7, March 1963, pp. 28-32.

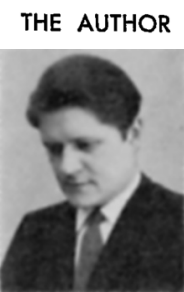

Gordon Mumma is a composer and concert performer. He was born in Framingham, Massachusetts, in 1935, and studied at The University of Michigan. From 1959 to 1963 he worked with the Operations Research department and the Acoustics and Seismics Laboratory of The University of Michigan Institute of Science and Technology.

As a composer in the electronic-music medium he has made motion-picture soundtracks for The University of Michigan Audio-Visual Center and for several independent film producers, and music for the Space Theatre productions be ing presented at the "Teatro Spettacolo" section of the Venezia Biennale in Italy during September 1964. In addition to establishing the Cooperative Studio for Electronic Music, his collaboration with the composer Robert Ashley includes the presentation of the annual ONCE Festival of contemporary music in Ann Arbor, and a concert tour called "Now Music for Pianos."

Mr. Mumma is presently engaged in the design of modulation procedures and apparatus for electronic music, and in composing a soundtrack for filmmaker Milton Cohen. 